\title{
Avant-garde Pedagogical Practise Utilizing Virtual Environments and Machinima in Systems Development
}

\author{
doi:10.3991/ijet.v5s1.1193 \\ N. Dreher and H. Dreher \\ Curtin University, Perth, Western Australia
}

\begin{abstract}
Inspired by the success of the Students @ Work project [1] run at Hamburg University, Curtin University (Perth, Western Australia) has recently concluded the running of a pilot course in Second Life with their Information Systems Project (ISP) students. The need for a change was evident as student motivation and engagement in the Final Year ISP course was strikingly low. Left with such a tall order for improvement, the ISP teaching staff looked to find suitable options for change. Staff combined new and interesting tools in an effort to boost and maintain student interest, specifically the Second Life virtual environment and a screen capturing technique known as Machinima.
\end{abstract}

Index Terms - collaborative learning, Machinima, pedagogical issues, virtual learning environments.

\section{INTRODUCTION}

In recent years, along with the downturn in popularity of Information Systems courses, the authors have been experiencing a drop in student motivation in the final year systems development course. Students were unmotivated, lacking in commitment to engage in learning experiences and as a result were not performing in their project tasks or demonstrating retention of new knowledge.

Adopting a constructivist approach, teaching staff have redesigned the third year Information Systems Project (ISP) to use a business case set up in a virtual world and have students engaged in analyzing, designing, implementing, testing, and documenting business processes. Students use the features provided in the virtual world Second Life, including programming in Linden Scripting Language (LSL), and interoperating with other useful web based tools and environments.

In order to document their achievements students make a Machinima documentary that describes the business case and depicts the solution artifacts actually being used by inworld avatars.

A final stage of learning involves reflection upon coursework by presenting and reviewing the Machinima in a forum of peers and discussing the shortcomings and improvements that could be made.

\section{OVERVIEW}

This paper begins by delivering an overview of the specific issues and needs of students that provided the impetus for ISP course redesign, followed by an explanation of the theoretical understandings that guided the direction of this redesign. The pedagogical benefits of Second Life will be outlined and illustrated within the context of this case example, followed by a mirrored examination of Machinima and its merits as an instructional device. In the final pages, the specific structure of the redesigned ISP course will be included along with a summary of student responses to the pilot course structure. Lastly as an appendix, we will share our experiences as novice Machinimatographers and Second Life developers.

\section{A MUlTi-FACETED LACK OF LEARNER MOTIVATION}

The final year ISP course in the Bachelor of Commerce (Information Systems) program is designed to allow students to demonstrate, in a real world situation and working on a real business case, their amalgamation of knowledge and skills gained in the area of Information Systems Design and Development during the previous two years of their Bachelor program. Formerly, student projects in this course were situated in real world business cases that students needed to find either via their own contacts, or were selected from a small set of pre-arranged business problems. The main objectives of the course were: to provide students with a real world systems development project with a business client, so that upon graduation they will have an understanding of the systems development process as practiced in today's business and technical environment, and be able to point to a successful systems project in which they have been involved; to develop the ability to apply technical, managerial, and interpersonal and communication skills to a realistic, moderately complex system development project implemented on a team basis; and, to be able to synthesize and integrate information systems, systems analysis and systems design in the development of computer based information systems.

Despite expectations of enthusiastic engagement with these rich learning opportunities, students gradually lost intrinsic motivation to work on their projects. The lack of motivation was the result of several contributing factors that were both observed by teaching staff and articulated by students via course evaluation surveys.

\section{A. Testimonial and observational understandings}

The most pertinent of these factors included the expectations of the business owner clients whom students were working with in their real business cases - the justifiably high expectations of business owners (naturally wanting the very best for their businesses) consistently surpassed students' developing abilities. This mismatch had a lamentable and frequent tendency to overwhelm students; a 
situation often resulting in a loss of intrinsic motivation, leading to poor learner self-efficacy, compounded by client dissatisfaction with final project outcomes. This frequently led to a breakdown in communication between students and their clients and often resulted in a situation where students were left unable to critically reflect upon learning outcomes via feedback from their clients, thus undermining the overall learning process and students' understanding of their achievements.

Another pertinent factor, which served to undermine students' understanding of their learning processes was the unfortunate tendency for students to lose motivation toward the end of their projects when it became necessary to begin the written documentation. Upon closer examination of this situation, two key contributing factors became clear: students found it impractical to look back upon their ten week system development project from the end and report on all key decisions as much had happened in this time and was difficult to remember; students also found that the production of lengthy written documentation was an anticlimactic and anti-motivational event given the activities of the previous ten weeks.

Other contributing factors included: the number of student group projects and the disparity between them, which made it virtually impossible for teaching staff to stay abreast of individual group progress and effectively guide students in order to assist in their construction and understanding of new knowledge; and a problem serving to amplify all others in that students did not wish to engage with the unavoidable programming requirements of these projects - a considerable number demonstrated the preference to adopt web-development projects as these were more "fun".

\section{B. Inspirations from constructivism}

From a pedagogical perspective it is clear that these factors combined are enough to warrant the need for course redesign - students were clearly not learning from their experiences as they were not provided with a positive and encouraging environment, rich with useful feedback and reflective opportunity. In order to successfully understand this lack of motivation and develop an effective alternative method for course delivery, it is necessary to take a closer look and explore the underlying factors. Already proponents of the constructivist method of teaching, ISP teaching staff turned back to the theory in an effort to analyze the course's shortcomings and find some meaningful answers.

It is a necessary component of the ISP course that students are given the opportunity to amalgamate their three years of learning and apply this to a real business case, giving them a taste of the real world of Business Systems Development. From a surface perspective this seems like a fantastic and motivational opportunity for students to branch out and get noticed in the business community however, as we have seen, students are pressured by such a situation as they simply do not yet have the skills necessary to function (without guidance and support from senior workers) in a real world business environment and perform to high expectations. If we consider this from a constructivist perspective it becomes apparent that students, in order to learn most effectively, need staged guidance from an instructor. Vygotsky described this as the learner's zone of proximal development, where it is necessary for learning tasks to be set at a level specific to the learner's abilities - if the task becomes too easy the learner will lose motivation due to boredom, and if the task is too difficult then motivation will be lost due to frustration - staged guidance is necessary in order to maintain motivation and allow for learning to take place [2].

The range of different student group projects is another demotivating factor which can be understood by Vygotsky's zone of proximal development - if an instructor is unable to stay abreast of student work, then their ability to monitor students' relative zones of proximal development is greatly diminished. This perhaps speaks of the need for less variety between student group projects, an idea which could be met with criticism. However, if the variety were decreased and teacher support then increased as a direct result, arguably the learning benefits would outweigh any advantages that variety offers - especially if the variety of projects is not as a result of student choice but as a result simply of the availability of business clients and their particular needs.

Constructivism asserts that above all else, learning, regardless of the topic, must be contextualized in such a way that is relevant to the world of the learners. Such material will motive learners because it supports the way in which humans learn most effectively, by linking new information to existing concepts and understandings [3].

It is a given that "Motivation is a key component in learning. Not only is it the case that motivation helps learning, it is essential for learning." [4]. Indeed, Oblinger and Oblinger [5] suggest that 'Net Generation' learners (also known as Gen Y) are motivated by learning which caters to their generational traits; learning which makes use of visual-spatial skills and allows for inductive discovery (discovery learning or active learning), attentional deployment (ability to shift attention rapidly between tasks) and fast response times (which Gen-Y students are capable of and expectant of).

Therefore it is important to look at the current cohort of students and find clues as to what interests motivate them so that these might be harnessed in the curriculum and used to help students to remain engaged with their learning and benefit from these experiences. It is clear in our ISP course that written systems documentation and textoriented programming is not what motivates students.

ISP teaching staff were left with the complicated question of how to provide students with real business problems without the mismatch between ability and expectation; and to do this in such a way that would allow staff to keep abreast of student progress in order to facilitate suitable guidance - thus positively affecting student motivation.

\section{ReinVigorating LEARNER MotiVAtion With SECOND LIFE}

Evidently, it was necessary to find an alternative method of delivery for the ISP unit, one that both satisfied the course outcomes and addressed the factors negatively impacting on student motivation. Inspired by the success of the "Students at Work" project at Hamburg University [1], ISP teaching staff decided to examine Second Life as a viable platform for course delivery.

A virtual reality, which is designed to mimic the real world as closely as possible, Second Life offers many of the same interactive opportunities that are available in the 
real world. From our theoretical examinations it was fathomable that Second Life would provide students with the necessary tools and options to fulfill relevant course outcomes, including: goal-oriented group collaboration; implementing system development methodologies; using system development tools; designing, constructing, testing and implementing a computerized information system; creation of a project plan; and, documentation to support implementation and continued use of the computerized information system.

However, more importantly for our purposes, course delivery in Second Life could be used to improve the student experience by removing the pressures and limitations of real-world project development that had been negatively affecting their learning experiences.

The issue of diminishing learner motivation levels and self-efficacy due to mismatched business owner expectations with students' developing abilities can be addressed through the use of Second Life - staff are given the ability to construct virtual world installations, which place the students inside simulated business problems that can be targeted to develop their specific levels of skill and knowledge gaps. Thus the role of business-owner is simulated by teaching staff and demands are kept to a level at which students can be challenged yet are still capable of developing a solution for in their ten weeks. Motivation levels are boosted by these experiences in success and students are driven to continue applying and developing their skills and knowledge.

As staff have created and are actively involved in managing the business projects, they are able to more effectively monitor student progress and provide useful guidance where and when needed, even if students are unaware that they are in need of help.

In order to monitor student progress, staff can to login to Second Life at anytime (from an on-campus or other location) and interact with or observe students as they work on their projects - this provides for flexibility in scheduling meeting times and also the opportunity for staff to monitor student progress as it suits, thus increasing the effectiveness of guidance and feedback in accordance with a student's zone of proximal development.

Further benefiting students, Second Life's dynamic environment, rich in visual-spatial stimulation is by its very nature uniquely suited to the traits of Gen Y learners. Promoting inductive discovery, it requires learners to explore the world, discovering how to best interact with it and spend time working with object-oriented scripting blocks in order to construct tools for use in-world, or to interoperate programs and databases from outside the virtual world. In this environment, scripting (previously a tedious task) becomes a visual-spatial experience where students receive instantaneous 3D visual feedback for their efforts - students turn to thinking more about how they can make their SL object (prim) do interesting, impressive and useful things (via programming) rather than focusing on the chore and boredom of programming per se.

The volume of raw programming necessary can be significantly reduced as per the will of students. This is largely due to the nature of LSL, the programming language used in Second Life. This language is open-source and easy to learn; students are able to find existing applications in Second Life and reuse the code for their own purposes. Many Second Life developers sell (for nominal amounts) and freely share their code via in-world trading with Linden Dollars (a virtual currency which is exchangeable with real world currencies - roughly LD1000 to USD2.50). When a coded object is bought or shared for the special sum of zero LD, it comes with a certificate for use - thus representing permission to reuse that code. Restrictions for use (e.g. no modification) can be specified by the creator and applied to the object before it is sold.

Further benefits provided by course delivery in Second Life are realized when systems documentation is constructed and delivered in the form of a Machinima, rather than the previous format of written documentation.

\section{REINVIGORATING LEARNER MOTIVATION WITH MACHINIMA}

\section{A. What is Machinima?}

Machinima (muh-sheen-eh-mah) is a relatively new, little known and evolving filmmaking technique - it is an example of 'emergent gameplay', a term used to express the creative use of video game tools. The definition offered by the Academy of Machinima Arts \& Science describes Machinima as, "the convergence of filmmaking, animation and game development. Machinima is realworld filmmaking techniques applied within an interactive virtual space where characters and events can be either controlled by humans, scripts or artificial intelligence." [6]. Traditionally the Machinima screen recording technique had been used to create non-narrative based animated game 'walkthroughs' (an alternative to the traditionally text-based forms) - increasingly Machinima is used to create narrative adaptations as well as original narrative scripts situated in unaltered as well as modified game world environments - the Academy of Machinima Arts and Sciences holds a yearly film festival for such creations. Virtual worlds such as Second Life, due to their adaptability and user-friendliness, provide ideal platforms for the production of Machinima.

\section{B. Benefits of Machinima to ISP students}

The major issue of inadequate reflection upon learning experiences on behalf of students can be creatively addressed via course delivery in Second Life. Through the use of the Machinima screen capturing technique, students can document all essential aspects of their projects in rich, visual/audio detail, thus providing a critically rich, reflective learning experience that is reusable.

The creation of written system documentation is carried out at the end of a ten week long system development project and is often seen by students as a necessary yet nevertheless unwelcome task. The purpose of this documentation is to provide students with the opportunity to reflect upon their learning, highlight the systems development concepts which guided their progress, and act as a medium through which feedback can be gained from others. As valuable as this experience is, the production of written documentation holds a fundamental drawback, which often undermines the effectiveness of the task as a reflective pedagogical device and a forum through which feedback is gained.

From a pedagogical perspective, looking back upon learning only when a task is finished is an ineffective learning experience - in order to be most successful re- 
flection upon learning should be carried out in synchronicity with project development - when left until the final stages the reflective process often results in an effort that is disconnected from project development. By this late stage of a ten-week project students may have forgotten many key decisions that led to their final information system product, and also missed opportunities to evaluate their current progress and avoid making costly mistakes during project development. Lastly, to write such long documentation after the practical experiences of the past ten weeks is an anti-climactic and consequently demotivating task.

Substituting a written approach with Machinima documentary sets the parameter that students will need to capture and document in-world footage at key intervals throughout their project development, thus allowing for ongoing/synchronous reflection. This new parameter serves to break up the task of documentation into smaller more motivationally sustainable segments and reduce the task of compiling documentation once project development is complete. In this way it can be seen that substituting the written approach with a Machinima documentary increases the likelihood that students will engage, at a worthwhile level, in critical reflection of their business process decisions and outcomes both during and after the project development stages.

In previous semesters when students lacked the motivation to properly complete the written documentation, this led not only to a loss of marks but also a poor feedback response from the presentation attendees due to the insufficient evidence provided by students.

In their Machinima, as in their previously written documentation, ISP students needed to include evidence of: ongoing critical reflection upon information systems project development and decisions made; critical reflection upon final project outcomes; and, a working instructional demonstration of the final computerized information system.

Previous groups of students had given their presentations in a format somewhat in accordance with the following: delivery of a written/verbal account of key project parameters and decisions leading up to completion; followed by a live demonstration of the finished working model; and, concluded with a summary and invitation for questions from the audience. This method was fraught with two main issues: audience members found the initial written/verbal spiel boring and difficult to follow at times, and were often distracted by the anticipated working demonstration to come. To compound factors, the working demonstration often carried out live, involved several wasted minutes spent on setting up, and was reliant on a stable internet connection without interference from proxy servers, firewalls, or other institutionally specific security measures. In short the live demonstration was fraught with problems that served to interfere with students' presentations and challenge the concentration span of audience members. When presentations followed suit in this manner, the feedback response from audiences was low and often filled with comments that were unhelpful to students, as audience members had not been given the chance to fully appreciate the final outcomes of project work.

As the students thought about what they needed to do to prepare a presentation of their work to an invited audience, they saw that the process of creating a machinima was both efficient and very effective, offering several benefits, including: a motivationally inspiring method of information delivery (as previously explained); a viable alternative to the written medium that was not more challenging to develop; and a method of information delivery uniquely suited to gaining enthusiastic feedback and fast response times.

Using Machinima to assist in their presentations, students integrated their written/verbal account of key project parameters and decisions, with screenshots and footage from the Second Life environment. Such visuals were key in highlighting specific points for an audience to appreciate. The working demonstration of project outcomes was now a pre-recorded and edited Machinima which showed the final product working in a variety of flawless situations, no longer affected by previous limitations. Students were given the choice of whether to pre-record an informative voice-over, include the explanations as part of a character script, or to give a live voice-over and pause the footage when necessary. Audience responses to such interesting and successful presentation were enthusiastic and students found that they could revisit segments of the footage and specific screen shots in order to assist during the feedback process.

Nevertheless, despite these improvements, when considering Machinima as a viable alternative to a written medium, it is important to consider whether the process of creating a Machinima may result in an unreasonably time consuming task. Indeed if project creation were not carried out inside a virtual environment, Machinima would not be a plausible alternative due to this very consideration. However, when projects are developed within a virtual world environment, the production of a Machinima need not be any more time consuming than the task of creating a written presentation.

As students work on their projects in the virtual world, they are inherently creating all aspects necessary for their Machinima - the ISP business solutions created by the students provide the physical environment of the Machinima, while the in-world avatars previously used to build the world, now become the stage actors, playing out scenarios and interacting with the working business solution.

The task of capturing footage and editing this into a final product, if captured in stage intervals throughout project development, need not be any more time consuming than developing written documentation. Middleton and Mather [7] have made similar observations in their study on innovative approaches to Machinima within virtual world curriculum; "If a set is already established the production of a visual response is within the grasp of both students and academics, and this can be useful in offering visual feedback, especially where digital media-enhanced pedagogies are already used.”

As a format for visual feedback, Machinima has a twopronged nature: firstly to elicit feedback from an openforum presentation crowd; and secondly for students to review in order to permit a deeper level of reflection upon what has been done, how to improve and what has been learned. It is the very nature of Machinima as an immersive, visual medium that makes it such an effective form of visual presentation and feedback. By providing a format that allows for instantaneous absorption of ideas, students are able to receive valuable feedback from teach- 
ing staff and other key individuals attending the presentation, and also review their work many times over and instantaneously reflect upon their decisions. These opportunities are not nearly as accessible via the submission of written documentation, which takes time to be absorbed, reflected upon and responded to.

Machinima production for review and feedback has the added benefit of reusability. Student Machinima films can be repurposed by modifying voiceovers (e.g. to reformat the Machinima into a procedural document for future students who wish to view past projects) or, "by offering students Machinima stems that they are tasked with completing by introducing variables (e.g. decisions, viewpoints) and conclusions." [7]. In this sense Machinima can be used as a teaching tool. Additionally, Machinima films can be easily archived and added to a library of examples for future use [8] - this is especially beneficial when considering the sheer volume of student projects undertaken over time and the expense this would lead to if an attempt were made to archive a live example of each within its original real or virtual world environment.

\section{MACHINIMA AS AN INSTRUCTIONAL DEVICE}

This idea of using Machinima as a device for student reflection came upon the ISP teaching team whilst developing a Machinima of their own - for use as an instructional device intended to demonstrate to students what was expected in terms of project outcomes in Second Life. The ISP demonstration Machinima 'Australis 4 Learning' [9] (named after the location island of the ISP project) depicted a scene demonstrating the customer's visualization of their business once all information systems solutions had been finalized and implemented. The particular project given to students was to design one information system artifact of a lager integration of several systems, the result of which would function as a fully in-world Student Services virtual-campus system.

This method of instruction, rich in visual-spatial stimulation, served to provide students with a dynamic visualization of expected outcomes and to begin orienting them with the Second Life environment in which they would be spending their semester. Middleton and Mather [7] recorded similar observations; “...the academic believed machinima "interspersed in a lecture" would engage and interest students more than current methods and would be more "stimulating and exciting”." ISP students frequently referred back to the visualization Machinima in order to gain inspiration.

Whilst not possible in the pilot stages of implementation, in future runs of the ISP course it will be practicable to use student generated Machinima as examples to set and improve expected standards. Truncations of student generated Machinima could also be used to provide introductions to tasks that students need to complete [7].

\section{COURSE RE-DESIGN}

In order to make project development in Second Life a success, it was necessary to redesign lesson delivery to include an induction process into the world environment and tools of Second Life. Weeks one to four provided an introduction to Second Life and the Linden Scripting Language.

In the first lecture, students were introduced to Second Life, acquainted with the environment and shown the business case study machinima 'Australis 4 Learning'. In labs three to four, students were required to solve small tasks individually. The goal was to create a '6-pack of software artifacts', each of the six artifacts having the potential to make a useful contribution to the overall business case and the final product. Group work was deliberately avoided at this stage in order to provide the opportunity for every student to gain the same background knowledge.

These weeks were taught with the assumption that most students were not familiar with Second Life and had to learn everything from scratch. It was considered that students who had practice with online gaming or other virtual worlds might begin with an advantage; however, in our experience most students achieved a comparable proficiency in programming with LSL.

\section{STUDENT RESPONSES}

Concluding late May 2009, students of the ISP pilot course were asked to provide feedback on what was good, what was bad, and what needed to be changed right away. Generally, there had been a very positive result from students. As is evident from the feedback below, we have succeeded in capturing their attention, revitalizing the course, and facilitating the students' achievement of course outcomes and objectives.

TABLE I.

RE-DESIGNED COURSE OUTLINE

\begin{tabular}{|c|c|c|}
\hline Wk & Activities & Notes \\
\hline 1 & $\begin{array}{l}\text { Basic object creation and avatar } \\
\text { interaction }\end{array}$ & $\begin{array}{l}\text { Development of one } \\
\text { software artifact }\end{array}$ \\
\hline 2 & $\begin{array}{l}\text { LSL to create and control avatar } \\
\text { animation }\end{array}$ & $\begin{array}{l}\text { Development of one } \\
\text { software artifact }\end{array}$ \\
\hline 3 & $\begin{array}{l}\text { Analyze the AAL business case for } \\
\text { opportunities }\end{array}$ & $\begin{array}{l}\text { Document analysis } \\
\text { Development of two } \\
\text { software artifacts }\end{array}$ \\
\hline 4 & $\begin{array}{l}\text { Creation of a mechanism through } \\
\text { which information can be commu- } \\
\text { nicated between SL and the real } \\
\text { world }\end{array}$ & $\begin{array}{l}\text { Development of two } \\
\text { software artifacts }\end{array}$ \\
\hline $5-10$ & $\begin{array}{l}\text { Software development and solution } \\
\text { portfolio based on software artifacts } \\
\text { developed during weeks } 1-4 \text {. } \\
\text { Extending ideas into realistic } \\
\text { business solutions. }\end{array}$ & $\begin{array}{l}\text { Project tasks were } \\
\text { related to the main } \\
\text { theme of the island - } \\
\text { the Automated As- } \\
\text { sessment Lab [10]. }\end{array}$ \\
\hline $11-12$ & $\begin{array}{l}\text { Project presentation and demo } \\
\text { showing the implementation of } \\
\text { software solutions. }\end{array}$ & $\begin{array}{l}\text { Machinima format for } \\
\text { presentation. }\end{array}$ \\
\hline
\end{tabular}

TABLE II.

STUDENT RESPONSES

\begin{tabular}{|l|l|}
\hline \multicolumn{1}{|c|}{ Positives } & \multicolumn{1}{|c|}{ Improvements } \\
\hline$\bullet$ Free from real world limita- & $\bullet$ Insufficient time and resources \\
tions, allowing for potential for & $\bullet$ Restrictions inherent in Second \\
innovation & Life environment, e.g. LSL, Ava- \\
$\bullet$ Many ways to approach the & tar roles (landowner, officer, \\
same problem therefore en- & member) \\
couraging critical thinking and & $\bullet$ Focus on business principles of \\
creative problem solving skills & IS \\
$\bullet$ Fresh, fun and creative ap- & $\bullet$ Greater emphasis on communica- \\
proach to project management & tion skills development needed \\
$\bullet$ Parallels real-life experience & $\bullet$ Protecting the investment in \\
$\bullet$ Learner-centered discovery & creating objects in Second Life \\
learning & e.g. backup, archiving \\
\hline
\end{tabular}


However, there are things to improve, as can be seen in the right column of the table. Whilst one can be delighted with the positive responses, one also needs to adjust future course implementation and delivery so as to mitigate the negative. In the next semester that the course is offered we plan to provide real world and virtual world projects at the student's choice where practicable.

\section{CONCLUSION}

We set out to reinvigorate interest, motivation and delight students with a pedagogically sound final semester that was relevant and fun.

There are rewarding opportunities to enhance IS Education for students through innovative use of emerging technologies such as Virtual Worlds. The use of Second Life and the AAL business case as modeled therein, has offered students the chance of immersion in a protected and privileged real world-like environment, with instant lifelike feedback on their ideas, decisions, and constructions, without the usual penalty associated with making errors and yet with the benefit of intrinsic reward for success.

Students discovered a new and powerful means by which they could document information systems - the Machinima - which also served as an integral part of learning through doing and describing, followed by reflection and rewarding feedback.

As the use of ICT continues to evolve in the general community, educational institutions face the challenge of staying at the forefront of innovation and industry relevance - Virtual Worlds are one way of doing so that is both inexpensive and pedagogically beneficial.

\section{APPENDIX - MACHINIMA MAKING BASICS}

As early-stage developers, harnessing the pedagogical benefits of virtual world environment and the various benefits that they hold, we would like to include our personal experiences in making Machinima. We are by no means claiming to be experts in Machinima making, rather offering our experiences as guidance for other academics who would wish to experiment with Machinima as an instructional tool. These experiences are shared within the context that they occurred; teaching staff developing a rich media instructional tool in order to help students visualize the expected project outcomes.

The Machinima making process is very similar to the filmmaking process in the sense that it is a three-phase course of action involving a pre-production or preparatory stage, a production stage where the desired footage is captured, and finally the post-production editing of captured footage into a presentable format. There are many different methods of Machinima making as well as tools available in order to make the process easier.

\section{A. Pre-production}

For the purposes of making Machinima it is the preproduction phase, which requires the most attention and time invested. (For students, if a course is delivered inside a virtual world, then much of the pre-production sage can be completed as a part of coursework.) Pre-production in Machinimatography consists of: world environment building; character creation; prop creation; scripting; and, camera movement experimentation. The initial build of the virtual world environment is by far the most time consuming of these tasks. The best advice one can receive at this stage is to take seriously the importance of planning ahead. Discoveries with regard to the specific mechanics of the virtual world will have an impact upon what is possible in filming later and can influence the direction of the script.

\section{B. Production}

Before launching into the production phase, it is necessary to spend time selecting screen capturing and editing software. Media file formats and capture resolutions need consideration. We used Fraps (approx €25) and Adobe Premier (approx €950) encoding in raw AVI at 25fps. This approach resulted in one particularly inconvenient complication - the compressed AVI formats outputted by Fraps were not supported by Premier; thus making it necessary to capture everything in raw AVI. Working with such huge file sizes (uncompressed AVI at 25fps) will slow down other processes later on such as file transfers and rendering. Several screen capture and edit software packages are available, for example Camtasia (approx $€ 200)$.

Choice of capturing tools aside, the production phase is only as complicated as the requirements of the script - if there are plans for special lighting, intricate camera work and so on, then the production phase can become quite lengthy. However, if the focus is more on getting the impression across and not so much on fancy effects, then the production phase can be a relatively quick event. Rehearsals of character interactions and camera movements are recommended in order to achieve the best outcome.

\section{Post-production}

If all has been well prepared in the earlier stages, postproduction can be a fairly straightforward process involving editing sound and footage together, and capturing a few extra shots or sound clips if necessary. In order to avoid time wastage caused by the transferring of files, it is a good idea to make the editing machine the same one that the footage is captured on.

\section{Machinimatographer's Toolkit}

Below is a combination of items that are essential to Machinimatography and some which make life easier:

- Game Engine (online virtual reality world or computer game);

- Screen capturing software;

- Video editing software;

- Quality headsets (one for each avatar controller);

- Microphones (for ambient background noise and any dialogue not captured in-game);

- 3DX Mouse (great for smooth camera movements);

- Proficient use of in-world tools; and

- Computers with specs high enough to comfortably run the chosen engine and video editing software.

\section{REFERENCES}

[1] T. Reiners et al., “Campus Hamburg and Students@Work present Immersive E-Learning in Second Life,” in Proc. 2008 World Conference on Educational Multimedia, Hypermedia and Telecommunications, Chesapeake, VA., 2008, pp. 933-935.

[2] S. Chaiklin, "The Zone of Proximal Development in Vygotsky's Analysis of Learning and Instruction,” in Vygotsky's Educational 
Theory in Cultural Context, A. Kozulin et al., Eds. Cambridge, United Kingdom: Cambridge University Press, 2003, pp. 39-64.

[3] B. Harper and J. Hedberg, "Creating Motivating Interactive Learning Environments: a Constructivist View," in Proc. 1997 ASCILITE, Perth, WA., 1997 (c) ASCILITE. Available: http://www.ascilite.org.au/conferences/perth97/papers/Harper/Har per.html

[4] G.E. Hein, "Constructivist Learning Theory," in Proc. 1991 International Committee of Museum Educators Conference, Jerusalem, Israel, 1991 (C) ICOM CECA. Available: http://www.exploratorium.edu/IFI/resources/constructivistlearning .html

[5] D.G. Oblinger and J.L. Oblinger, "Is it Age or IT: First Steps Toward Understanding the Net Generation," in Educating the Net Generation, D.G. Oblinger and J.L. Oblinger, Eds. Washington: Educause, 2005, pp. 2.1-2.20. Available: http://www.educause.edu/educatingthenetgen

[6] (2005, August 3). The Machinima FAQ [Online html]. Available: http://www.machinima.org/machinima-faq.html

[7] A.J. Middleton and R. Mather, "Machinima interventions: innovative approaches to immersive virtual world curriculum integration,” ALT-J, vol. 16, no. 3, pp. 207-220, Sept. 2008. (doi:10.1080/ $\underline{09687760802526723}$

[8] J. Richter et al., "Critical Engagement of Teachers in Second Life: Progress in the Salamander Project," in 2007 Second Life Education Workshop - Second Life Community Conv., Chicago, 2007, pp. 19-26.

[9] H. Dreher. (2009, July 24). Australis 4 Learning [Online mp4]. Available: http://www.eaglesemantics.com/webfm

[10] H. Dreher et al., "Design and Integration of an Automated Assessment Laboratory: Experiences and Guide," in Proc. 2008 EDMEDIA, Vienna, 2008, pp. 2858-2863.

\section{AUTHORS}

N. Dreher is with the School of Information Systems, Curtin University, Curtin Business School, WA 6102 AUSTRALIA (email: n.dreher@curtin.edu.au).

Naomi is a Research Associate for the Semantic Analysis and Text Mining for Business and Education (SATM4BE) research group at Curtin University. She also teaches Information Technology at Cyril Jackson Senior Campus, a Perth secondary school for mature-aged and refugee students. In her undergraduate studies Naomi completed a Bachelor of Communications with Honours; she also has a Diploma of Information Technology and a Graduate Diploma of Secondary Education. As an early career researcher, Naomi is focused on developing her experience as an educator and further researching in the field of computer assisted teaching and learning.

H. Dreher is with the School of Information Systems, Curtin University, Curtin Business School, WA 6102 AUSTRALIA (email: h.dreher@curtin.edu.au).

Heinz is Professor in Information Systems at the Curtin Business School. He has published in the educational technology and information systems domain through conferences, journals, invited talks and seminars. Dr Dreher's research and development program is now supported by Curtin Business School Area of Research Focus funding - Semantic Analysis and Text Mining for Business and Education (www.eaglesemantics.com) in addition to other competitive funding obtained for individual projects.

This article was modified from a presentation at the International Conference of Interactive Computer Aided Learning ICL2009, September 2009 in Villach, Austria. Submitted 11 September 2009. Published as resubmitted by the authors on 17 January 2010. 